\title{
APONTAMENTOS SOBRE O CAMPO DAS RELIGIÕES AFRO-BRASILEIRAS E SEUS AUTORES REVISITADOS
}

\author{
Gerlaine Martini ${ }^{1}$
}

Resumo: Trata-se de reflexão baseada na revisão de autores e autoras pesquisadores pioneiros em um recorte que ressalta sua inserção no campo religioso afro-brasileiro, com enfoque em seu nível de participação nos rituais e em como isso interferiu em seus estudos e obra, e com a análise de como a visão dos religiosos informantes contribuiu para delinear linhas de pesquisa informais e perspectivas teóricas inclusive as mais abrangentes.

Palavras-chave: religiões afro-brasileiras; observação participante; iniciação; ogã; equede.

\section{Introdução}

A principal motivação para esse artigo foi o encontro que aconteceu recentemente, em meados de 2016, no Instituto de Ciências Sociais (ICS) da Universidade de Brasília, em meio ao clima ainda vigente das reviravoltas políticas no país, entre diversos acadêmicos da área de Ciências Humanas interessados em estudar e em debater autores que tenham escrito sobre as religiões afro-brasileiras ${ }^{2}$, nas suas diversas modalidades - candomblé, terecô, tambor de mina, xangô, umbanda, batuque, cabula e tantas outras que constituem esse campo que passamos carinhosamente a denominar como "calundu", de forma a abarcar essa pluralidade.

O termo "calundu" não apenas carrega o significado que remete às raízes coloniais dessas manifestações como foi historicamente usado para se referir ao conjunto das práticas religiosas fora da ortodoxia católica, principalmente as de caráter afro-ameríndio (SOUZA, 2000) ${ }^{3}$. Esse caráter afro-ameríndio por sua vez está também fundado na memória da origem de seus elementos entre vários e diferentes povos africanos e indígenas, até hoje preservada em algumas das modalidades mencionadas.

${ }^{1}$ Doutora em Antropologia pela Universidade de Brasília. Integrante do Calundu (Grupo de Estudo sobre Religiões Afro-Brasileiras).

${ }^{2}$ Depois veio se juntar ao nosso grupo um acadêmico cubano ligado a uma religião afro-cubana, ampliando ainda mais essa perspectiva.

${ }^{3}$ Segundo Vivaldo da Costa Lima (1984: 21), "calundu" é sinônimo de inquice, portanto, de orixá e de vodum. 
Retomar o termo "calundu" nesse novo contexto - conforme o consenso produzido pelo encontro de nosso grupo - coloca ênfase nessa diversidade e na abertura que reúne as diversas tradições e comunidades religiosas numa convivência positiva, nesses tempos em que o combate à intolerância religiosa é o que mobiliza encontros e atuações mais imediatas.

Nosso interesse enquanto grupo pelas religiões afro-brasileiras, e pelo estudo de autores que pensaram e pesquisaram nesse campo, logo se revelou para além da academia. Cada integrante tinha uma história que o ligava às comunidades religiosas de maneira muito pessoal, alguns tendo nascido e se criado nessa ambiência, outros tendo sentido uma conversão ao longo de seu contato ou trabalho com essas comunidades. Assim, fomos entendendo que essa nossa especificidade nos fazia buscar revisitar e rever os estudos afro-brasileiros, juntando dois mundos em um só. Esse artigo visa começar a refletir sobre essa busca da revisão autoral mediada pelos vários níveis de pertencimento às tradições religiosas afro-brasileiras.

\section{Os primeiros estudiosos e sua participação ritual}

As religiões afro-brasileiras têm sido um campo bastante explorado pela pesquisa em ciências sociais e na abordagem histórica. Creio que, ao tocar as representações e imaginários de povos que se encontraram neste território, numa longa história de inteirações duradouras, esse campo atravessa pontos cruciais ou nodais. Dentre estes, o comentário de forma concentrada das questões raciais no país, que são transversais aos segmentos, classes e categorias sociais, somando-se este comentário às visões alternativas de gênero baseadas em valores de origem não europeia. Esse campo também expressa algo que, embora pareça não nos deixar ser completamente "modernos"4, relaciona-se, pela mesma atuação, à resistência secular dos setores oprimidos pela dominação colonial.

Esse não foi um campo que se constituiu de maneira homogênea. Conforme nos indica Vagner Gonçalves da Silva (2000) - declaradamente um adepto do candomblé que pesquisou especificamente o trabalho de campo e o texto etnográfico das pesquisas antropológicas sobre religiões afro-brasileiras - muitos dos autores clássicos em estudos afro-brasileiros não eram especificamente cientistas sociais, apesar de os procedimentos

${ }^{4}$ Refiro-me ao conceito de Bruno Latour (2009). 
de campo, por eles adotados, terminarem se consolidando como forma de atuação dos pesquisadores dessa área.

Deste modo, o pioneiro Nina Rodrigues, falando a partir do final do século XIX, era médico. Manuel Querino fez parte do movimento social como abolicionista, líder operário e professor de arte. Arthur Ramos foi um médico que pretendia dar continuação ao trabalho de Nina Rodrigues com o universo religioso afro-brasileiro nos anos 30 - embora tivesse se tornado posteriormente professor de antropologia da Faculdade Nacional de Filosofia. Édison Carneiro, na mesma década, era formado em direito e atuava como jornalista e folclorista. Pierre Verger era fotógrafo francês - um ofício que não está totalmente apartado do próprio ato da observação participante ${ }^{5}$. E as mulheres pesquisadoras formaram um caso à parte.

Porém, mesmo partindo de outras áreas, de uma forma ou de outra, em sua maior parte, os estudiosos terminaram se aproximando da abordagem antropológica. Os procedimentos adotados por esses autores clássicos e que se consolidaram foram em grande medida "justapostos à técnica da observação participante, reivindicada como método por excelência da antropologia, em períodos mais recentes, por autores comprometidos com a legitimação e profissionalização dessa disciplina" (SILVA, op. cit.: 16). E foi assim que as religiões afro-brasileiras vieram se conformando como um dos mais explorados objetos de nossa antropologia.

$\mathrm{Na}$ época da produção desses estudos clássicos ${ }^{6}$, num ambiente menos definitivo institucionalmente, outros fatores interferiram na constituição de objetos etnográficos de maior relevância. Determinados confrontos acabaram por emoldurar essa área de pesquisa, muito próximos das próprias rivalidades e disputas que despontavam entre as diferentes vertentes das tradições afro-religiosas em pauta e que não deixavam de possuir um sabor de regionalismo - que também definiria determinados "centrismos", muito criticados posteriormente, em relação ao recorte e à seleção de campos para o trabalho da pesquisa.

Nesse sentido, Mariza Corrêa (2003) identifica dois grupos, um deles de baianos (incluindo estudiosos de outros estados que fizeram suas carreiras na Bahia), “intelectuais de província” que teriam se mudado para a o Rio de Janeiro, capital do país nesse período, onde atuaram conjuntamente numa espécie de “operação de guerrilha

\footnotetext{
${ }^{5}$ Aqui são mencionados autores que trabalharam com comunidades religiosas afro-baianas, e esse recorte se relaciona com o pioneirismo e a uma configuração regional de intelectuais como veremos adiante.

${ }^{6}$ Estamos falando num período inicial que abrange o final do século XIX e a primeira metade do século $\mathrm{XX}$.
} 
Revista Calundu - vol. 1, n.1, jan-jun 2017

cujo objetivo parecia ser destronar a posição, que começava a ganhar foros de hegemonia, de Gilberto Freyre, no campo do estudo das relações raciais" (op. cit.: 167). A outra vertente seria, portanto, a dos pernambucanos, e argumentos estratégicos foram contrapostos pelos baianos a esta vertente com o objetivo mais imediato de questionar a artificialidade de sua teoria da "mestiçagem":

Três elementos pareciam se constituir, assim, nos signos de diferenciação entre baianos e pernambucanos: a primazia no estudo das relações raciais, atribuída pelos primeiros ao médico Nina Rodrigues; a evidente ênfase dos baianos numa atuação política; e, o que foi a marca do seu trabalho nessa época, a "africanização" da Bahia, com tudo o que isso implicava - a começar pela eleição de certos centros de culto como "puros", por oposição aos cultos "híbridos" (CORRÊA, 2003: 167).

Não podemos ignorar que essa configuração reverberou, de maneiras talvez inesperadas, até o cenário contemporâneo dos estudos afro-brasileiros e que a visibilidade da questão racial viria atrelada ao que mais tarde passou a ser caracterizado pejorativamente como uma postura teórica "nagocêntrica". As posições teóricas iniciais desposadas por ambas vertentes carregavam em si ideias equivocadas sobre a miscigenação da população vista ou como biologicamente degenerativa ou como uma solução de "melhoramento racial" (o que viria a ser discutido como "branqueamento"). Abandonados os determinismos e as naturalizações, a discussão se manteve com o conceito de raça como categoria social em ação e com consequências ainda atuais, o que hoje se reconhece no repertório jurídico, por exemplo, que define a discriminação racial como tipo penal.

Porém, enquanto ainda grassavam mentalidades que naturalizavam categorias raciais, a divisão regional entre "baianos" e "pernambucanos", relativa a posicionamentos teóricos que se pretendiam mais abrangentes, provavelmente era reforçada pelas diferenças regionais entre comunidades afro-baianas e afropernambucanas.

Coincidentemente, a rivalidade entre as comunidades religiosas de Pernambuco e da Bahia acontecia nesse período, pelo menos conforme notou Pierre Verger, que fotografou etnograficamente os xangôs de Recife no final da década de 40, antes de focar mais estritamente o universo afro-baiano e antes de se aproximar da academia. Em solo baiano, na casa de um sacerdote que tinha vindo de Recife e foi um de seus principais informantes (Pai Cosme), Verger tirou uma foto polêmica, mostrando detalhes cruentos de cerimônias fechadas, com a permissão deste oficiante, no intento 
de provar aos candomblés baianos que em Recife existiam sacerdotes capazes de realizar os mesmos rituais que aconteciam no território soteropolitano (VERGER, 1991:176).

Esse assunto tão específico levantado por Pierre Verger toca na questão de "pureza" dos cultos e seu maior nível de "africanidade", supramencionados na citação7, pois as comunidades de casas de Salvador e Recife pareciam estar disputando em relação à detenção do saber de práticas rituais autenticamente "nagôs" (especialidades religiosas africanas dos iorubas do Benim), o que seria uma categoria, portanto, local.

Assim, essa não é simplesmente uma visão exterior do fotógrafo francês, interferindo em seu campo de pesquisa, quando este ainda nem se considerava pesquisador $^{8}$. É uma predisposição já interior às comunidades, que pode ser conferida pelo posicionamento de um dos principais informantes soteropolitanos desses primeiros autores, Martiniano do Bomfim, conforme veremos adiante; e como nos relata sobre ele Donald Pierson (1942: 33): “Conhece tão bem as 'coisas africanas' que é ocasionalmente chamado a Pernambuco (...) para executar ritos especiais que os membros do culto nessa cidade são incapazes de realizar". 9

Mãe Aninha (Eugênia Anna dos Santos, 1869-1938), fundadora do Ilê Axé Opô Afonjá, de quem Martiniano era amigo e consultor, expressa claramente esse valor dado a uma autenticidade "nagô" (PIERSON, op. cit.:28; NÓBREGA, 2000, explicitando a autoria de Aninha): D. Aninha afirmava com orgulho: "Minha seita é nagô puro como (no) Engenho Velho ${ }^{10}$. Tenho ressuscitado grande parte da tradição africana que mesmo o Engenho Velho tinha esquecido".

Constatada a transposição dessa perspectiva de alguns terreiros para um plano teórico abrangente, fica a indagação sobre em que medida um campo (o acadêmico) de algum modo refletia, com seus filtros, o outro (as comunidades afro-religiosas), através das redes de relações que se formavam. Essa relação tão intrincada fica mais em evidência ainda ao se comprovar a constante participação religiosa, em algum nível, de

\footnotetext{
${ }^{7}$ Definições em grande parte superadas no âmbito acadêmico. Em relação à "pureza" ver discussão de Beatriz Góis Dantas (1988) e seus desenvolvimentos.

${ }^{8}$ Posteriormente foi sugerida a relação de Verger com "resíduos coloniais" (SANTOS, 1982). Verger recebeu bolsas do Institut Français D'Afrique Noir (IFAN) para realizar a pesquisa comparativa com o Brasil, numa época em que o regime político francês já começava a enfrentar o processo de independência de países africanos em relação ao seu domínio.

${ }^{9} \mathrm{~A}$ disputa no caso não se constrói sobre a representação da origem (nagô em relação ao congo-angola ou ao caboclo), mas sim sobre a deficiência regional brasileira de um culto que seria da mesma origem africana.

${ }^{10}$ Terreiro da Casa Branca (Ilê Axé Iya Nassô Oká), matriz do Terreiro Opô Afonjá. Lima (op. cit.: 19) observa que Aninha falava da origem deste, já que ela era descendente de grunces do norte de Gana.
} 
estudiosos nos terreiros afro-brasileiros. Lisa Earl Castillo (2008) faz relato minucioso sobre essa situação, no caso baiano, de quem me valho substancialmente para essa breve descrição, ainda que incompleta, sobre a integração dos primeiros etnógrafos às comunidades.

De modo talvez surpreendente, parece que a Faculdade de Medicina da Bahia em Salvador tinha relações muito próximas com o Terreiro do Gantois (Ilê Iya Omi Axé Iyamassê) e que Raymundo Nina Rodrigues (1862-1906) inaugurou uma regra na relação entre várias gerações de pesquisadores ligados à faculdade e o terreiro: professor maranhense na Faculdade de Medicina, Rodrigues foi suspenso ogã ${ }^{11}$ do Gantois.

Também teve acesso ao peji pessoal de Martiniano do Bomfim (segundo o próprio Martiniano) - um quarto de santo ${ }^{12}$ residencial com os assentamentos (objetos de culto) herdados dos próprios pais consanguíneos do religioso - que é sinal de certa consideração por parte deste respeitado e referido babalaô. Pode-se perceber como o posicionamento teórico de Nina Rodrigues $^{13}$ não impedia que sua atuação preservacionista (fruto do conservadorismo equivocado) fosse relativamente interessante perante os terreiros.

Martiniano Elyseu do Bomfim (1859-1943), nascido no Brasil e filho de pais africanos (origem ijexá e egbá), foi o jovem auxiliar de pesquisas de Nina Rodrigues, justamente por ser letrado em inglês e na ortografia das palavras iorubanas, além de falar português, e de trazer consigo as experiências vividas na cidade de Lagos (atual Nigéria) quando lá morou durante onze anos. Ele continuará sendo um dos principais informantes entre duas gerações de pesquisadores e sua perspectiva centrada em determinadas origens - que eram as das tradições familiares que lhe antecediam - das práticas religiosas africanas no Brasil será filtrada para as pesquisas.

O sacerdote e antropólogo Julio Braga (1999: 48-9) classifica Nina Rodrigues como um ogã de fora, não escolhido na malha interna da comunidade, mas como alguém que prestava um precioso auxílio, humanizando assim as ações do médico, que não eram totalmente incoerentes com a mentalidade que este partilhava com teorias em voga na época, pela qual foi criticado posteriormente:

\footnotetext{
${ }^{11} \mathrm{Um}$ posto masculino e de prestígio na hierarquia religiosa, o que será discutido mais adiante.

${ }^{12} \mathrm{Um}$ santuário, conforme classificavam etnograficamente os primeiros autores, que podemos considerar um altar, mas não exatamente um altar com imagens antropomórficas elevadas.

${ }^{13}$ Evolucionismo (darwinismo social, naturalização de desigualdades sociais) e patologismo, "marca de todos os autores da época" (Monique Augras, 1983: 44).
} 
Nina Rodrigues terminou por ser escolhido como ogã de um dos mais prestigiosos terreiros da época, o do Gantois. Ressalte-se o caráter humanístico de Nina Rodrigues, que provavelmente não se recusava a intermediar interesses de pessoas dos candomblés dentro da sociedade mais ampla, tampouco deixar de atender como médico um negro doente e prescrever-lhe algum tratamento, ou encontrar, com a ajuda de seus colegas de profissão, um apoio qualquer para atender a gente pobre de Salvador, aviando uma receita, facilitando um internamento na incipiente rede hospitalar da época.

Julio Braga (op. cit.: 58; SILVA, 2000: 94; 2006: 290) ainda comenta que Nina Rodrigues não foi simplesmente um ogã de fora e um ogã suspenso (conforme CASTILLO). Suspenso (tirado) significa apenas escolhido para ser ogã, o que é demonstrado numa cerimônia pública pelo ato simbólico de ser levantado numa cadeira e nela carregado, porém que precisa ainda ser confirmada, realizando-se rituais na casa onde foi escolhido. Ele se confirmou como ogã do orixá Oxalá no Terreiro do Gantois por Mãe Pulquéria (Pulchéria Maria da Conceição Nazareth, 1841-1918), filha brasileira da fundadora da casa (africana que Rodrigues chegou a conhecer ${ }^{14}$ ):

Embora seja difícil acreditar que Nina Rodrigues comungasse da experiência religiosa afro-brasileira, tornou-se, pelo fato de ser pesquisador e, por força disto, frequentador assíduo do candomblé, um de seus aliados políticos que podia, de certa maneira, tomar posições públicas contra as perseguições policiais. Isso lhe deu crédito na comunidade religiosa, que findou por estabelecer com ele laços mais sólidos de participação no contexto dos rituais (BRAGA: 58).

Ou seja, o médico parece ter se submetido aos devidos rituais, que o próprio Julio Braga (op. cit.: 62; cf. 74-5) conclui serem rituais de iniciação próprios dessa categoria nos candomblés tradicionalmente: "Caso não se submeta a essa iniciação, permanecerá na categoria de ogã suspenso, sem merecer os benefícios e o tratamento que têm aqueles que assim procederam”.

Nessa perspectiva, Nina Rodrigues teria sido iniciado, embora não comungasse da experiência religiosa por causa de sua postura intelectual. Mas se a participação nesses rituais puder ser pensada de maneira integral e corporificada, a suposta "falta de comunhão" seria restringida à sua consciência mental do que ele declarava ser um animismo de forma exterior fetichista (RODRIGUES, 1988: 163). De alguma forma, o médico passou pela gamela do feitiço (termo usado por Braga, que também pode definir a imersão em ritual reservado).

Gonçalves da Silva (2006: 294) discorre sobre essa posição ambígua do pesquisador do mundo das religiões afro-brasileiras em relação à fé religiosa, levando a

\footnotetext{
${ }^{14}$ Maria Julia da Conceição Nazareth (1800-1910).
} 
conflitos entre éticas religiosas ou a uma aceitação dos valores da religião "sem uma adesão subjetiva a eles", e afirma que, nesse campo específico, não se exigem provas de uma conversão internalizada:

Principalmente nas categorias de ogã e equede, que não prescrevem a necessidade do transe, e para as quais os antropólogos são geralmente requisitados, a crença íntima raramente é questionada. (...) Muitos pesquisadores que, frequentemente, se filiam aos terreiros, aderem muito mais a um estilo de vida e a um grupo de referência afetiva do que à religião propriamente dita.

José Bizerril $(2005,2015)$ toca nesta dimensão ao discutir a implicação prática da corporeidade do pesquisador como lócus de aprendizado cultural, ou seja, através da presença e da experiência vivida no corpo, uma tradição cultural exótica transforma-se em experiência vivida corporificada e plena de sentido. Transpondo este conceito para nosso tema, a confirmação de Nina Rodrigues como ogã, embora sem transe e a princípio isenta de sentimento religioso, torna-se ainda mais intrigante.

Se Rodrigues aceitou que práticas rituais fossem realizadas em seu corpo $^{15}$, mesmo que incredulamente, aquilo que este assim experimentou acrescentou muito à sua percepção, o que provavelmente transbordou em seu posicionamento perante a totalidade do tema ${ }^{16}$. Portanto, Nina Rodrigues inaugura uma corrente de pesquisa central sobre as religiões afro-brasileiras com o que se poderia chamar de observação altamente participante onde ser ogã era um procedimento de campo. Essa postura foi sendo repetida pelos autores que se seguiram, com fechamentos e aberturas cíclicos.

Manuel Raimundo Querino (1851-1923), que era natural de Santo Amaro da Purificação, também contatou e descreveu os cultos no mesmo período de Nina Rodrigues. Monique Augras (1983) o vê como "sob todos os aspectos, o oposto de Nina Rodrigues. É negro e pobre (...) participa ativamente da vida política de Salvador, defendendo os humildes, os artesãos, os operários de tal maneira que acaba sendo aposentado sumariamente".

Este autor também tinha sua cota de participação nas comunidades religiosas, tendo morado num bairro (Matatu de Brotas) com muitos terreiros que ele conhecia, inclusive o Terreiro de Procópio do Ogunjá, e tendo pertencido à irmandade negra Sociedade Protetora dos Desvalidos. Assim, por sua origem, haveria uma identificação

\footnotetext{
${ }^{15}$ Lembrando que ele conheceu Maria Júlia e foi suspenso antes de ser confirmado mais tarde por Pulchéria e que sua obra menciona a ambas frequentemente, ainda que de passagem (CASTILLO, op. cit.: 106). Ou seja, poderia haver um processo de inteiração e "conversão" em continuidade.

${ }^{16}$ Incluo aqui os desenvolvimentos (de forma indireta) que Dantas (1988:242) define como a transformação da "pureza nagô" de categoria "nativa" em analítica pelos antropólogos.
} 
maior de Querino com as comunidades de terreiro, embora não se retratasse, enquanto narrador, como parte delas. Parece que foi ogã do Gantois ${ }^{17}$ e sua própria filha também se tornou adepta deste terreiro (CASTILLO, op. cit.: 109).

Augras (op. cit.: 35) menciona com destaque que "as mais antigas fotografias que possuímos de um terreiro foram tiradas no Gantois por Manuel Querino, que destaca a beleza e a nobreza do porte de Pulquéria". Porém, Querino não fotografou propriamente Pulquéria e sua mãe Maria Júlia, mas teve acesso aos retratos destas e os publicou, o que demonstra interlocução com o Terreiro do Gantois, acrescida do atestado contato com Martiniano do Bomfim (CASTILLO, op. cit.: 110-12), assim como tinha ocorrido com Nina Rodrigues.

Mas essa proximidade via origem não transpareceu tanto em sua obra, mais propriamente descritiva, embora as descrições de pormenores litúrgicos ${ }^{18}$ denotem o que poderíamos chamar de uma observação "bem" participante, focalizada no cotidiano da Bahia. Augras (op. cit.: 45) define este trabalho:

Seus livros demonstram o empenho em retratar as artes da Bahia, desde as Belas-Artes até a arte culinária, mas se dedicam sobretudo a defender os homens de cor, sublinhando a importância da contribuição dos negros e mulatos na cultura brasileira. (...) quando tenta explicar as coisas que viu, no entanto, mostra-se legítimo representante do fim do século XIX. (...) Como se vê, em Querino, a inferioridade natural da mulher justifica aquilo que Nina Rodrigues explicava pela inferioridade natural do negro.

Ou seja, Querino naturaliza uma categoria cultural dos candomblés de seu campo, o transe predominantemente feminino, numa interpretação distorcida, mas que demonstra um nível mais sensível de seu conhecimento sobre o que acontece nestes terreiros. E, no entanto, para Julio Braga (op. cit.: 60-1), a descrição feita por Querino sobre o prestígio do ogã (embora também tenha relatado práticas rituais de suspensão e de confirmação), tende a reduzir e simplificar a dimensão religiosa do trabalho interno à comunidade feito pelo ogã (que Querino também o era), dimensão que Braga pretende resgatar com seu texto.

Apenas o autor Padre Étienne Ignace Brazil (1911), recentemente lido e debatido por nosso grupo, mostra-se então como uma das poucas exceções ${ }^{19}$ do início desse período clássico de estudo, por ser um padre e, portanto, não ter sido suspenso ogã.

\footnotetext{
${ }^{17}$ Pierson (op. cit.: 24) identifica-o como ogã do Gantois.

${ }^{18}$ Por exemplo, a referência a "favas brancas" como oferenda em A Festa de Mãe-D'Água (1938), texto que foi lido e debatido pelo Grupo Calundu.

${ }^{19}$ João do Rio (2015), apesar de uma rica fonte histórica de cinco matérias pioneiras publicadas na Gazeta de Notícias no início de 1904, não se coloca como um pesquisador, mas como repórter que beira a ficção.
} 
Revista Calundu - vol. 1, n.1, jan-jun 2017

Percebemos como provavelmente obteve suas informações de maneira menos comprometida que os outros autores (que se tornaram, ao menos, ogãs suspensos) através de suas próprias recomendações (op. cit.: 195):

Visitem os hospitaes, interroguem os velhinhos do Asylo de Mendicidade da Bahia, penetrem nos casebres e terreiros dos africanos, finalmente consultem os babalaos, e averiguarão que a cabala negra é profusamente espalhada entre os homens de côr. (...) Animado pelo favorável veredictum dos competentes, pesquizámos novos dados, mórmente na Capital Federal, onde estudámos a collecção africana do Museu Nacional.

Em parte do trecho citado, são referidas como "dados novos" as imagens reproduzidas, no texto, dos objetos da denominada coleção africana do Museu Nacional - como machados, abanadores e outras ferramentas rituais. Tais imagens remetem à perseguição policial sofrida pelos candomblés (criminalizados até o fim da década de 70) expropriados de seus instrumentos litúrgicos, mas que o padre acredita serem objetos de "fetichismo", "tolerado pelos poderes públicos".

E o não comprometimento de Étienne Brazil é tão explícito que ele classifica as práticas dos candomblés como "nojentas". O seu preconceito e rejeição, soando às vezes num tom inquisitorial, que denota sua exterioridade em relação às comunidades religiosas, fazem-no adotar uma atitude mais cínica sobre a transparência e a indução do discurso dos religiosos (em contraponto aos estudiosos ogãs suspensos):

É mister interrogar centenas de crentes para extrahir uma restea de luz desse mar de treva. Além disso, o Africano apparece desconfiado ante o homem culto. Por isso nem de leve se póde crêr em seus assertos.

Não podendo oppôr o silencio em descaminho de nossas pesquizas, valem-se do embuste. Para elles, a desconfiança é mãe da segurança; pelo que cuidadosamente occultam seus Manipanços, e vedam aos profanos o ingresso em seus Pejis (sanctuarios) e celebram seus candomblés nos terreiros isolados e inacessíveis aos menos iniciados. Perguntados acerca de suas crendices, não raro se furtam por meio de respostas evasivas e ambigüas. O único meio de se lhes desvendar os segredos - é o dinheiro (BRAZIL, op. cit.: 202-3).

Tais palavras revelam as dificuldades com que o padre deve ter se deparado e provavelmente os subterfúgios que deve ter tentado usar, acreditando que alguma coisa substancial poderia ser revelada ao se pagar pela informação ${ }^{20}$ (sem a compreensão do próprio repertório de onde ela vem), quando o principal critério para um entendimento maior do que se passava nas tradições afro-brasileiras já se revelava ser, até mesmo através de Nina Rodrigues, um comprometimento além do exercício intelectual.

\footnotetext{
${ }^{20}$ Nilma Lino Gomes (2006: 235-6) menciona este percalço no campo de Ruth Landes e o analisa.
} 
Elas também ressaltam o valor do acesso ao peji, mencionado anteriormente, e das cerimônias iniciatórias como propiciadoras de abertura para o vislumbre dos rituais internos e genuínos nas casas. Apesar do esforço esboçado, são exibidos dados muito desencontrados em seu texto (veja o quadro comparativo de BRAZIL, op. cit.: 209). E ele é criticado por Arthur Ramos (2001: 62, nota 82) que fala de seu trabalho como "eivado de senões", inclusive em função de uma leitura apressada de Nina Rodrigues e de João do Rio, "sem cotejar os dados com observações diretas".

Mais adiante no tempo, Ignace Brazil ainda se destaca como exceção, visto que seu crítico Arthur Ramos (1903-1949), alagoano também ligado à Faculdade de Medicina da Bahia, (da geração logo após Nina Rodrigues) foi do mesmo modo suspenso ogã do Terreiro do Gantois, conforme o costume, fato que o próprio autor descreve:

Neste ponto, as observações de Nina Rodrigues e Manuel Querino foram confirmadas pelas minhas próprias, pois, para fins de pesquisa científica nos submetemos, eu e meu prezado amigo, o Dr Hosannah de Oliveira, docente da Faculdade de Medicina da Bahia, a cerimônias de iniciação de ogãs no Terreiro do Gantois (RAMOS, op. cit.: 62).

Logo em seguida, este mesmo autor continua descrevendo, na terceira pessoa, uma cerimônia de suspensão, que Julio Braga, ao citar esse excerto, sugere ser a sua própria suspensão como ogã. Assim, Arthur Ramos se autodescreve como ogã suspenso com a finalidade científica de pesquisar as comunidades religiosas afro-brasileiras, e continua a descrição falando rapidamente da necessidade de confirmação posterior.Vemos aqui um menor comprometimento, mas ainda uma boa proximidade do terreiro $^{21}$.

Ao longo da obra, Arthur Ramos abandona as naturalizações anteriores de raça e se dedica a categorias agora consideradas culturais - em relação ao pensamento de gênero não faz tantos avanços. Será a partir dele que os "baianos" vão formar o grupo acima mencionado, o qual desde o princípio tinha fortes ligações com o universo dos terreiros afro-baianos.

Édison Carneiro (1912-1972), nessa época, fazia parte da "escola" de Arthur Ramos, com quem tinha uma relação assimétrica ao representar "o jovem mulato baiano procurando o apoio do professor de medicina, branco, já consagrado" (CORRÊA, op. cit.: 173). Esta se configurava como uma relação com direito a provocações de Ramos,

\footnotetext{
${ }^{21}$ Embora Ruth Landes, após a convivência com as comunidades religiosas de Salvador, duvidasse que Arthur Ramos fizesse trabalho de campo (CORREA, op. cit.: 245, nota 29).
} 
seja nas avaliações desaprovadoras à publicação do pai de Édison Carneiro sobre mitos africanos no Brasil, seja nas ameaças de pesar a mão da crítica sobre o trabalho de Ruth Landes, a pesquisadora estrangeira com quem Carneiro teve uma relação amorosa (OLIVEIRA; LIMA, 1987: 31; CORREAA, op. cit.: 169; 241: nota 13; GOMES 2006: 251: nota 4) - antropóloga à qual o próprio Ramos havia indicado Carneiro como guia.

Como era já de costume, Carneiro foi suspenso ogã (do orixá Xangô), só que desta vez no terreiro da então proeminente líder Mãe Aninha, o Ilê Axé Opô Afonjá, que irá se destacar no mesmo papel que o Terreiro do Gantois cumpriu anteriormente. Porém, Carneiro não se confirmou, o que lhe dava certa vantagem ao ser disputado por outros dois terreiros que também o suspenderam (ou seja, o indicaram para confirmação) - a casa matriz do Ilê Axé Iya Nassô Oká (Terreiro do Engenho Velho) e o Terreiro do Ogunjá de Pai Procópio, conforme o próprio Édison Carneiro em uma nota do livro de Ruth Landes (2002: 197: nota 31): “Eu era então disputado como ogã pelo Engenho Velho e pelos candomblés de Aninha e de Procópio, mas não me 'confirmei' em nenhum”. Julio Braga (op. cit.: 55) descreve como funcionava essa situação:

Se, por um lado, a situação de ogã suspenso limitava sua participação no interior do candomblé, por outro este status certamente facilitou suas andanças, pesquisas e estudos na Bahia. No caso em apreço, é possível que a situação de ogã apenas suspenso lhe permitisse transitar de um candomblé para outro, sem despertar as naturais reações de ciúme tão comuns, especialmente em se tratando de uma pessoa como Édison Carneiro, que se tornou um dos mais combativos defensores da religião do negro na Bahia.

Foi assim combativo que este participou do trabalho de divulgação positiva dos candomblés $^{22}$ a partir do II Congresso Afro-Brasileiro na Bahia em 1937 (posterior ao I Congresso Afro-Brasileiro em Pernambuco, e fruto da frente de atuação "baiana") onde tornou possível a apresentação inédita de textos de autoria de religiosos dos terreiros (fato muito interessante): Notas sobre Comestíveis Africanos (Mãe Aninha); Ligeira Explicação sobre a Nação Congo (Manoel Bernardino da Paixão do Terreiro Bate Folha); O Mundo Religioso do Negro na Bahia (Manuel Vitorino dos Santos, o Manuel Falefá da Formiga) e Os Ministros de Xangô, uma contribuição posterior de Martiniano do Bomfim (LIMA; OLIVEIRA, op. cit.: 29).

Carneiro chegou a fundar, no mesmo ano deste congresso, a União de Seitas Afro-Brasileiras da Bahia, tendo como primeiro presidente Martiniano do Bomfim

\footnotetext{
${ }^{22}$ Reticentes em relação às exposições, principalmente na imprensa, por causada perseguição policial acirrada desde a década de 20 e da extorsão através de licenças para realizar cerimônias públicas.
} 
(LIMA; OLIVEIRA, op. cit.: 30) que, como se pode perceber, mantinha relações com sucessivas gerações de estudiosos. Isto se refletiu até nos escritos dos estudiosos sobre as contribuições não iorubas, como a dos congos e angoleiros, para as comunidades religiosas de terreiro, segundo explica Castillo (op. cit.) e como vínhamos discutindo. Desta contribuição, Manuel Querino havia falado pioneira e isoladamente sobre candomblés de caboclo ${ }^{23}$, enquanto Édison Carneiro ensaiava escrever a respeito de comunidades declaradamente preservadoras das tradições religiosas da região africana Congo-Angola - que tinham aportado ao território brasileiro havia longo tempo - mas da perspectiva tendenciosa do seu informante babalaô.

Aliás, em relação aos primeiros escritos de religiosos, o autor maranhense Manoel Nunes Pereira (1892-1985) redigiu, ainda em 1942, A Casa das Minas. Segundo Augras (op. cit.: 48) esta obra:

(...) constitui o primeiro testemunho de observador que pertença à cultura do objeto de estudo. Nunes Pereira é mestiço e sua mãe era sacerdotisa em templo vodu de São Luís do Maranhão. Ele é o primeiro a dar testemunho de uma verdade interior, que pertence ao seu patrimônio pessoal (...). Consagrado desde pequeno a Badé, da família de Keviosso, o equivalente Gege de Xangô - é-lhe difícil levar a sério as interpretações euro-americanas. Nega que haja sincretismo com os santos católicos.

De modo semelhante a Manuel Querino, Nunes Pereira é alguém "de dentro", cujas práticas rituais sempre foram parte do cotidiano, tentando legitimar sua religião de origem para "fora", ao descrevê-la. Sobre os primeiros autores das religiões afrobrasileiras, alguns já mencionados até aqui, Julio Braga (op. cit.: 51) faz um arremate: “Os principais estudiosos do candomblé e da cultura negro-africana de maneira geral foram ou são ogãs e têm prestado relevantes serviços à preservação e valorização do aludido universo sociocultural".

Isso pode ser afirmado mesmo sobre os pesquisadores estrangeiros, que começaram a chegar desde meados da década de 30, franceses e estadunidenses, interessados nas populações de origem africana no Brasil. Dentre os pioneiros, temos Donald Pierson (op. cit.: 7) que se autodeclara ogan. Aliás, Corrêa (op. cit.: 174) ressalta Franklin Frazier como o único pesquisador negro norte-americano do grupo que veio ao Brasil e que era "não por acaso, o único dos pesquisadores sobre a situação do negro brasileiro que não se tornou ogã de nenhum terreiro da Bahia" (grifos meus).

\footnotetext{
${ }^{23}$ Num pequeno artigo de 1919 (CASTILLO, op. cit.: 110).
} 
Dos franceses, Roger Bastide (1898-1974), já professor de sociologia em São Paulo, conheceu pela primeira vez os terreiros de Salvador em 1944 e assistiu diferentes tipos de cerimônias, ainda sem dominar bem o português. Em sua segunda breve estadia soteropolitana (1949), pelo interesse em estudar a adivinhação, teria jogado búzios, sendo considerado filho de Xangô Ogodô (LÜHNING, 2002). Foi em 1951 que uma "lavagem de contas" no Opô Afonjá24 deve tê-lo tocado profundamente a ponto de afirmar, a partir desse contexto, “africanus sum” (BASTIDE, 1971: 44) no prefácio de sua tese sobre o candomblé, defendida em 1958, quando volta a residir na França. É bom lembrar que, nas suas observações pontuais, o autor afirma ter presenciado aparições em culto com invocação de espíritos de antepassados ilustres (SILVA, 2006: 303), literalmente fazendo um encontro etnográfico com o extraordinário, tema discutido por José Jorge de Carvalho (1993).

O viés africanista permanecia, mas Bastide já usava conceitualmente metáforas de situações de sua vivência interna ao terreiro em seus escritos, tais como a de uma cultura penetrando pelos poros ou a do alimento preparado ritualmente sendo portador do sabor e do saber. Contatos rituais esporádicos e profundos na vida agitada entre São Paulo, Salvador, Brasil e França definem o campo deste autor.

Pierre Fatumbi Verger (1902-1996), por sua mediação contínua com determinadas regiões na África (valorizando a "africanização"), reeditou aquela relação de abertura ao ritual da parte dos estudiosos para com as comunidades afro-brasileiras, instaurada antes por Nina Rodrigues, que ficava mais tênue ao se evitar a confirmação, conforme circunstâncias. E o fotógrafo fez isso buscando iniciações também na África.

Ele não era um pesquisador convencional e não se restringiu ao papel de um ogã suspenso. Foi com Mãe Senhora (Maria Bibiana do Espírito Santo, 1890-1967) a então líder do Opô Afonjá, que Verger realizou sua inserção ao terreiro em 1948, antes mesmo de iniciar seu percurso mais estritamente acadêmico: "Quando cheguei à África, Dona Senhora já tinha feito o bori sobre minha cabeça" (VERGER, 1995). Uma coincidência poderia ter motivado este vínculo religioso: Verger fazia aniversário muito próximo da data de iniciação de Mãe Senhora ${ }^{25}$. Em 1949, o autor partiu para pesquisar

\footnotetext{
${ }^{24}$ Michel Dion (2002: 129: n. 16) cita Bastide afirmando que uma cerimônia de bori só poderia ser feita após sete anos da lavagem (a qual o tornava apenas um "membro periférico"), e que ele o faria retornando ao Brasil - mas nessa data, em 1958, vai à África com Verger. Silva (2006: 290) declara que Bastide assentou seu santo no Opô Afonjá.

${ }^{25}$ Cf. Nóbrega (op. cit.: 14), embora as datas anuais do nascimento e da iniciação de Mãe Senhora estivessem sendo revistas.
} 
o Daomé e usou seu "colar de Xangô" como passaporte ritual ao atingir regiões nagôsiorubas. ${ }^{26}$ (VERGER, 1991: 173; LÜHNING, op. cit.: 47).

Verger ainda obteve iniciações na região de Ketu e na cidade de Saketê (atual Benim), entre 1952-53, inclusive como babalaô, recebendo um nome iniciático (Fatumbi) e adotando uma postura assumida de adepto (embora também um estudioso), por acreditar que isso lhe daria permissão para ter maior acesso e poder de preservação da liturgia à qual tinha sido iniciado no Brasil (VERGER 1982: 256): "O fato de ter-me tornado babalaô dava-me o direito e dever de aprender de meus confrades as histórias simbólicas sobre as quais repousa a adivinhação pelo Ifá e cujo conjunto representa a soma dos conhecimentos orais dos Iorubás". A função de babalaô se tornava, para Verger, como o equivalente tradicional africano-ocidental do estudioso e do pesquisador, um detentor de saberes. Por isso, declarava estar tomando, a princípio, notas para mostrá-las a seus amigos do candomblé mais do que qualquer outra coisa (VERGER op. cit.: 255).

A região africana onde se deram as iniciações foi escolhida por ser um lugar mais próximo das origens da comunidade baiana à qual se via pertencente (LE BOULER, 1994: 157). Depois, Verger adquiriu o cargo de oju obá (olho do rei) no Opô Afonjá; também foi indicado para ogã na Casa Branca (SILVA, op. cit.: 292).

Verger levou às últimas consequências a visão de uma origem africana muito local e específica à qual se deveria retornar, que teria sido elegida por casas que terminaram, devido a condições históricas, direcionando o campo de pesquisa em seus primórdios. Lima (1984: 22) define essa visão do fotógrafo como uma predisposição valorizadora da cultura nagô ${ }^{27}$ de Ketu: "Muita gente, Arthur Ramos, recentemente Roger Bastide e Pierre Verger, repetem essa forma etnocêntrica, esse pequeno desvio metodológico e teórico de considerar a teologia nagô mais desenvolvida (...)" (cf. LIMA 2003: 54). O fotógrafo também encontrou uma categoria local que acreditava definir o papel de pesquisador nessa região específica: o babalaô - justamente a profissão de Martiniano do Bomfim.

\footnotetext{
${ }^{26}$ Ao que parece, Verger (naquele momento) se situaria dentro da categoria masculina de ogã, por não conseguir se deixar entrar em transe, como declarava publicamente (o que ele atribuía à sua "mente cartesiana"). A categoria ogã abrange diferentes segmentos dentro dos candomblés, como ogã de sala, ogã alabê (tocador), etc. (BRAGA 1999).

${ }^{27}$ Os iorubas do Benim.
} 


\section{A Cadeira das Equedes}

Edison Carneiro (1969: 45) mencionou a cadeira das ekédis do Terreiro do Engenho Velho, e Arthur Ramos (op. cit.: 63) declarou: “As mulheres também podem ser sócias dos candomblés, como notou Édison Carneiro e se chamam ekédi”. Mais recentemente, Augras (op. cit.: 200) descreve equedes já consagradas fazendo uma "cadeirinha" com seus braços cruzados para carregar uma mulher da assistência eleita pelo orixá para ser nova equede, de modo semelhante à suspensão masculina ${ }^{28}$. Porém, em relação às pesquisadoras, essa associação específica não foi tão marcante como no caso dos ogãs.

Temos três casos emblemáticos sobre pesquisadoras pioneiras das comunidades de terreiro afro-brasileiras, estrangeiras que se envolveram de modo diverso. Ruth Landes (1908-1991), antropóloga estadunidense na Bahia, é descrita como alguém que experimentou emoções despertadas pelas cerimônias de candomblé, o que lhe fez entender o trabalho de campo como uma filosofia de vida, enquanto realizava uma “quebra do predomínio masculino na intelectualidade que escrevia sobre o candomblé nas décadas de 30 e 40" (GOMES, op. cit.: 232; 240). Assim, por ter deixado transparecer sua subjetividade como pesquisadora, num relato coloquial das várias vozes de seu campo, e por procurar entender o que pesquisava a partir de uma ótica das relações de gênero num recorte incomum à época, Landes foi recuperada no final da década de 80 por antropólogas feministas (CORRÊA, op. cit.: 241: nota 12; GOMES, op. cit.: 233), quando tinha seu trabalho sido muito criticado desde sua pesquisa em 1938:

As análises até agora feitas a respeito da perseguição que Ruth Landes sofreu por parte de Arthur Ramos e Melville Herskovits parecem assentar-se sobre três pontos: primeiro, em sua atuação como pesquisadora, isto é, tanto pelo fato de ser uma mulher entrando num campo dominado por homens, quanto pela sua relação amorosa com Édison Carneiro, seu guia no mundo dos candomblés; segundo, por sua ênfase nas relações raciais, num momento em que a antropologia passava a dar ênfase a explicações culturais ${ }^{29}$; e terceiro, por sua descrição, destoante das descrições canônicas, a respeito da importância que as mulheres tinham nos terreiros de candomblé (CORRÊA, op. cit.: 169).

\footnotetext{
${ }^{28}$ Vivaldo da Costa Lima (2003: 88) vê as equedes como funcionalmente distintas dos ogãs, com deveres de "caráter muito mais pessoal".

${ }^{29}$ Para Gomes (op. cit.: 243), Landes tem uma visão idílica das relações raciais no Brasil por causa mesmo de um viés culturalista e pela insistência na comparação apressada com os EUA.
} 
Mesmo partilhando da mentalidade em voga com perspectiva convencional de gênero, e mesmo ainda em concordância com a maioria dos pesquisadores na época (e com seu informante Martiniano) na tendência a valorizar "pureza" e "africanização", Landes destoa das descrições de estudos anteriores por conseguir enxergar um princípio de feminilidade que ia além dos sujeitos da situação observada:

(...) ao colocar as mulheres no topo e os homens na base, Landes invertia a classificação simbólica da relação masculino/feminina da sociedade na qual esses cultos se inscreviam. Assim, o princípio feminino - ainda que parte dele corporificado em homens - é que dominaria o conjunto do campo das religiões afro-brasileiras na Bahia, com a marginalização do princípio masculino (CORRÊA, op. cit.: 171).

A interpretação de Ruth Landes dá um salto qualitativo em relação ao que Querino já havia percebido anteriormente sobre o transe feminino (cf. supra). Curiosamente, como Nina Rodrigues, Ruth Landes também teve acesso ao peji de Martiniano do Bomfim (já bem mais velho), por ela descrito como um cômodo sem janelas com estatuetas de deuses em estilo africano ("tão preciosos para os estudiosos"), "pedras-fetiche" e oferendas (LANDES, op. cit.: 277-8). A autora não parece se incluir entre os estudiosos que menciona, mas declara em seu relato a certa altura (op. cit.: 260): "Senti que me tornara africana nos meus preconceitos, tão africana quanto Martiniano, Menininha e Luzia”. Sobre isso, Gomes (op. cit.: 242) observa "“A contaminação da antropóloga' pela cultura afro-brasileira e sua relação pessoal com o culto do candomblé são também críticas dirigidas à autora e sua obra".

As políticas de gênero da academia somadas a sua condição numa sociedade onde as mulheres que circulavam sozinhas eram encaradas com suspeita demonstra em grande parte porque Landes não inaugurou uma linhagem tão coesa como a que vimos se delinear com os pesquisadores que foram sendo suspensos ogãs, apesar dela possuir atributos para tanto. Não é improvável que, para além deste contexto, o princípio feminino dominante que a própria autora descobriu estivesse em ação, colocando as mulheres preferencialmente não como "sócias do candomblé", mas como a parte central - apesar de não exatamente evidente - que busca alianças e associações periféricas.

Este pode ter sido o caso atípico de Gisèle Omindarewá Cossard (1924-2016). Sua pesquisa aconteceu quase em decorrência de sua iniciação, não como equede, por entrar em transe, o que radicalizou sua inserção na religião e no campo. O processo de sua iniciação meio repentina com Joãzinho da Goméia (João Alves Torres Filho, oriundo da Bahia, 1914-1971) numa tradição angola em 1959, a se desenrolar no Rio de 
Janeiro, tornou Gisèle uma figura única. Porém, bem antes de chegar ao Brasil como esposa do conselheiro cultural da embaixada da França, era familiarizada com diferentes mundos africanos e já havia conhecido boa parte da África, tendo vivido alguns anos no continente e tendo inclusive nascido no Marrocos, quando sua família francesa ali morou.

Gisèle se tornou uma estudiosa realizando um percurso paralelo ao seu amadurecimento dentro dos rituais afro-brasileiros, sempre enfrentando problemas de permanência no Brasil. Alguns anos após sua iniciação, ainda noviça, ela passou a escrever artigos sobre temas das religiões afro-brasileiras, como a música ou o comportamento da filha de santo, com enfoque no condicionamento do estado de transe e em seu caráter não patológico, até obter seu doutorado na França:

Ela entra em contato com Roger Bastide e se inscreve para uma tese de doutorado de terceiro ciclo em sociologia. Ela não tem uma formação nem diploma de sociologia, mas Roger Bastide confia nela e a orienta em suas leituras básicas. Também lhe deixa a livre escolha quanto ao conteúdo de sua pesquisa. No primeiro encontro, ele apenas lhe disse: "A senhora sabe muito mais do que eu, escreva!" (DION, op. cit.: 73)

Anos depois, em 1970, defendeu sua tese baseada no ritual angola ao qual ela tinha sido iniciada, mas tendo descrito na realidade uma mistura de tradições iorubá e angola (DION, op. cit.: 75) e neste mesmo ano recebeu o grau ritual para se tornar uma mãe de santo (sacerdotisa zeladora), fato que se consolidou apenas em 1976, após fundar seu próprio terreiro em Duque de Caxias (Baixada Fluminense). Foi deste modo que terminou acessando uma parte central da religião (que mencionamos acima como a área do "feminino dominante") ao mesmo tempo em que possuía, então, qualificação acadêmica. Preocupada em traduzir e legitimar aquilo que vivenciava, colocando a religião em primeiro plano, não deixou de, por vezes, usar sua tese como um álibi para explicar suas relações com o candomblé em ambientes preconceituosos (op. cit.: 81). Como pesquisadora, manteve-se em temas discutidos por Landes, ao falar sobre o transe em geral vivido por uma mulher (AUGRAS, op. cit.: 76-7) e ao tentar abordar o papel da mulher negra nas religiões afro-brasileiras num artigo em 1974 (DION, op. cit.: 95).

Nas décadas seguintes, seguiu sendo "a francesa da Goméia", enquanto estudiosos e religiosos atravessavam processos de mudança, até que reescreveu suas descrições do candomblé num livro que foi lançado em 2006, corrigindo o que considerava um ponto fraco em sua tese (op. cit.: 75) ao abordar explicitamente as três 
Revista Calundu - vol. 1, n.1, jan-jun 2017

tradições que compõem o candomblé em cada componente litúrgico: tradição congoangola, tradição jeje e tradição ketu, sobre o que ela conclui (COSSARD 2014: 13):

Anteriormente o candomblé era visto como um mundo oculto, para iniciados. Aos poucos, pesquisadores, especialistas e até sacerdotes começaram a divulgar este conhecimento de forma fragmentada. Acredito que, na verdade, tudo já tenha sido dito, mas de forma dispersa e muitas vezes com interpretações intelectuais, que reconstroem uma visão fora da realidade do candomblé.

O saber que Bastide atribuiu a Omindarewá - visão e experiência dentro da realidade do candomblé - foi descrito como método por mais uma pesquisadora pioneira das religiões afro-brasileiras. Juana Elbein dos Santos, de origem argentina, que primeiro estudou medicina e passou à psicanálise (AUGRAS, op. cit.: 52), antes de se dedicar à antropologia, reúne características das duas mulheres anteriores. Foi casada com um religioso e artista plástico, Deoscoredes Maximiliano dos Santos (1917-2013) do Terreiro Opô Afonjá que, similarmente a Querino, transcreveu as tradições de seu povo (op. cit.: 52), enquanto a tarefa de interpretar o material coube mais à sua esposa. O acesso ao que Gomes (op. cit.: 248-9) chama de "capital de campo" (familiaridade via relações interpessoais) proporcionou a Juana Elbein base para sua interpretação teórica:

Com a publicação de Os nagô e a morte, livro de Juana Elbein dos Santos apresentado como tese de doutorado em etnologia na Sorbonne, pela primeira vez, numa etnografia acadêmica, defendeu-se a iniciação do pesquisador como um princípio metodológico legitimador da observação participante (SILVA 2006: 293).

Ou seja, a iniciação foi proclamada como garantia na precisão dos dados relatados na tese, defendida em 1972: uma reconstrução do "sistema nagô" que, no entanto, Verger questionou usando como critério sua própria vivência e obtenção de dados diferenciada (SILVA 2000: 131-2). Mesmo com esta polêmica, a obra de Juana Elbein seguiu sendo uma referência. A descrição poética da sua iniciação gerou reflexões interessantes por parte de Juana Elbein, no que diz respeito ao que pode ser considerado, segundo Carvalho (op. cit.: 99), uma gnose extraída da observação participante:

A transmissão e apreensão do conhecimento não se adquirem por leitura, por raciocínio lógico, não apenas a nível consciente e intelectual. A transmissão se realiza de modo ativo, dinâmico e interpessoal carregando a experiência, o hálito, a história pessoal e grupal, os gestos, a respiração dos mais antigos aos mais novos, de geração em geração, assegurando a corrente "consanguínea" entre os iniciados, entre passado, presente e futuro, renovando o pacto (SANTOS; NOBREGA, op. cit.: 41-3). 
O saber iniciático descrito como método fecha um círculo, ao retornar à vocação professada por Martiniano do Bomfim, de babalaô e de guardião do conhecimento e das histórias de sua tradição e, por que não dizer, de sua co-autoria na abordagem acadêmica dos estudos sobre religiões afro-brasileiras, somada às contribuições das/os líderes dos terreiros nas diversas tradições. Pode-se concluir sobre este resumido panorama de alguns dos primeiros estudiosos que há uma tendência que reforça o que vem sendo discutido sobre as equivalências entre trabalho de campo e iniciação, como caminhos entrelaçados com pontos em comum, com questões intrigantes que merecem aprofundamento. Mas isso já fica pra outra história...

\section{Referências Bibliográficas}

AUGRAS, Monique. O Duplo e a Metamorfose. Petrópolis: Vozes, 1983.

BASTIDE, Roger. As Religiões Africanas no Brasil. São Paulo: Livraria Pioneira; Editora da Universidade de São Paulo, 1971.

BIZERRIL, José. "Espiritualidades asiáticas, experiencias meditativas y subjetividades corporificadas". In: CITRO, S.; BIZERRIL, J.; MENNELLI, Y. (orgs). Cuerpos y corporalidades en las culturas de las Américas. Buenos Aires: Biblos, 2015, p. 259272.

"Mestres do Tao: Tradição, Experiência e Etnografia". In: Horizontes Antropológicos, vol. 24 Antropologia e Performance, Porto Alegre, PPGAS UFRGS, ano 11, p. 87-105, jul./dez. 2005.

BRAGA, Julio. A cadeira de Ogã e outros ensaios. Rio de Janeiro: Pallas, 1999.

BRAZIL, Étienne Ignace. "O Fetichismo dos Negros do Brazil". In: Revista do IHGB. Rio de Janeiro: IHGB, T. 74, v. 124, 1911, p. 193-160.

CARNEIRO, Edison. Candomblés da Bahia. Rio de Janeiro: Edições de Ouro, 1969.

CARVALHO, José Jorge. "Antropologia: saber acadêmico e experiência iniciática”. In: ANUÁRIO Antropológico 90. Rio de Janeiro: Tempo Brasileiro, 1993, p. 91-107.

CASTILLO, Lisa Earl. Entre a oralidade e a escrita: a etnografia nos candomblés da Bahia. Salvador: EDUFBA, 2008.

CORRÊA, Mariza. Antropólogas \& Antropologia. Belo Horizonte: Editora UFMG, 2003.

COSSARD, Gisèle Omindarewá. Awó: o mistério dos orixás. Rio de Janeiro: Pallas, 2014. 
DANTAS, Beatriz Góis. Vovô Nagô e papai branco: usos e abusos da África no Brasil. Rio de Janeiro: Graal, 1988.

DION, Michel. Omindarewa: uma francesa no candomblé, a busca de uma outra verdade. Rio de Janeiro: Pallas, 2002.

GOMES, Nilma Lino. "Caminhando com Ruth Landes pela Cidade das Mulheres". In:FONSECA, Maria Nazareth Soares (org.). Brasil Afro-Brasileiro. Belo Horizonte: Autêntica, 2006.

LATOUR, Bruno. Nunca fomos modernos. São Paulo: Editora 34, 2009.

LE BOULER, Jean P. (org.). Alfred Métraux \& Pierre Verger: le pied à l'étrier Correspondance 1946-1963. Paris: Jean Michel Place, 1994.

LIMA, Vivaldo da Costa. A família de santo nos candomblés jejes-nagôs da Bahia: um estudo de relações intragrupais. Salvador: Corrupio, 2003.

"Nações-de-candomblé". In: Encontro de nações-de-candomblé. Salvador: Ianamá; CEAO; UFBA, 1984.

LIMA, Vivaldo da Costa; OLIVEIRA,Waldir Freitas (orgs). Cartas de Édison Carneiro a Artur Ramos. São Paulo: Corrupio, 1987.

LÜHNING, Angela (org.). Verger-Bastide: dimensões de uma amizade. Rio de Janeiro: Bertrand Brasil, 2002.

NÓBREGA, Cida da; SANTOS, José Félix dos(orgs). Maria Bibiana do Espírito Santo, Mãe Senhora: saudade e memória. Salvador: Corrupio, 2000.

PIERSON, Donald. O Candomblé da Baía. Curitiba: Editora Guaíra Limitada, 1942.

QUERINO, Manuel. “A Festa de Mãe D’Água”. In: Costumes Africanos no Brasil. Rio de Janeiro, 1938, p.: 60.

RAMOS, Arthur. O Negro Brasileiro. Rio de Janeiro: Graphia, 2001.

RIO, João do. As religiões no Rio. Rio de Janeiro: José Olympio, 2015.

RODRIGUES, Nina. Os Africanos no Brasil. São Paulo: Ed. Nacional. Brasília: Ed. Universidade de Brasília, 1988.

SANTOS, Juana Elbein dos. Os Nàgô e a morte: Pàdè, Àsèsè e o culto Égun na Bahia. Petrópolis: Vozes, 1993.

"Pierre Verger e os resíduos coloniais: o 'outro' fragmentado". In: Religião

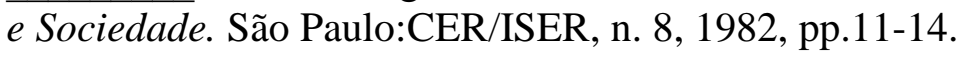

SILVA, Vagner Gonçalves da. "Observação Participante e Escrita Etnográfica". In:FONSECA, Maria Nazareth Soares (org.). Brasil Afro-Brasileiro. Belo Horizonte: Autêntica, 2006. 
O Antropólogo e sua Magia: Trabalho de Campo e Texto Etnográfico nas Pesquisas Antropológicas sobre Religiões Afro-brasileiras. São Paulo: Editora da Universidade de São Paulo, 2000.

SOUZA, Laura de Mello e. Revisitando o Calundu. São Paulo: Universidade de São Paulo, 2000.

VERGER, Pierre Fatumbi. "Uma vida na contramão". In: Revista Marie Claire. São Paulo, n. 55, 1995.

“Entretien avec Emmanuel Garrigues”. In: L'Ethnographie. Paris: Société d'Etnographie, n. 109, 1991, pp. 167-178.

50 Anos de Fotografia. Salvador: Corrupio, 1982. 